\title{
ESTRUTURAS E FUNDAMENTOS SOCIAIS: A LEITURA HONNETHIANA DE HABERMAS
}

\author{
Hélio Alexandre da Silva \\ Herbert Barucci Ravagnani $(\dagger)^{2}$
}

\begin{abstract}
RESUMO: O presente artigo pretende sublinhar, na forma de breves apontamentos gerais, os contornos mais amplos da crítica de Honneth a alguns aspectos do pensamento habermasiano. Tal crítica é norteada especialmente por uma investigação dos critérios morais e normativos das lutas sociais que Honneth recupera, por meio de uma apropriação crítica do pensamento do jovem Hegel. O ponto central defendido por Honneth é que as possibilidades da experiência interativo-comunicativa não podem ser resumidas ou tomadas exclusivamente na interação linguística, nem mesmo esta última pode ser perseguida em seu aspecto ideal, sem a pressuposição dos contextos conflituosos nos quais ela sempre está inserida.
\end{abstract}

PALAVRAS-CHAVE: Conflito Social. Intersubjetividade. Habermas e Honneth.

\section{INTRODUÇÃO}

Axel Honneth construiu nas últimas décadas uma obra que, em grande medida, parte de uma análise do pensamento de Habermas e procura apontar limitaçôes na abordagem linguística do paradigma da intersubjetividade e suas implicaçóes para a Teoria Crítica. Sua crítica central se pauta na tese de que as possibilidades da experiência interativo-comunicativa não podem ser resumidas ou tomadas exclusivamente na interação linguística, nem mesmo esta última pode ser perseguida em seu aspecto ideal, sem a pressuposição dos contextos conflituosos nos quais ela sempre está inserida ${ }^{3}$. Nesse sentido, o

\footnotetext{
${ }^{1}$ Doutor em Filosofia pela UNICAMP. Professor Adjunto da UESB - Universidade Estadual do Sudoeste da Bahia. E-mail: helioale@yahoo.com.br. Dedico este artigo ao seu coautor, Herbert Barucci Ravagnani, querido amigo falecido em janeiro de 2013.

${ }^{2}$ (07.02.1986-17.01.2013) - Professor de Filosofia no Instituto Federal de Educação, Ciência e Tecnologia de Goiás, mestre em Filosofia pelo Programa de Pós-Graduação em Filosofia da Faculdade de Filosofia e Ciências da UNESP/Marília.
}

${ }^{3}$ HONNETH, A. The critique of power: reflective stages in a critical social theory (1991), p. 298-300. 
presente artigo pretende sublinhar, na forma de breves apontamentos gerais, os contornos mais amplos da crítica de Honneth a alguns aspectos do pensamento habermasiano. Tal crítica será norteada especialmente por uma investigação dos critérios morais e normativos das lutas sociais que Honneth recupera, por meio de uma apropriação crítica do pensamento do jovem Hegel.

A partir da sua inserção no contexto da tradição da Teoria Crítica, iniciada principalmente com Critica do poder: estágios reflexivos de uma teoria critica da sociedade, de 1985, Honneth tem procurado conceituar o conflito social enquanto luta por reconhecimento. Desse modo, ele compreende as esferas sociais do reconhecimento como algo que compóe os fundamentos da realidade social ${ }^{4}$ a partir de onde é possível extrair critérios para uma teoria moderna do reconhecimento e da justiça. Essa nova abordagem proposta por Honneth visa a "[...] elucidar categorialmente a realidade social" ${ }^{5}$, situando o conflito social e os sentimentos de desrespeito e injustiça no centro da Teoria Crítica. Assim, Honneth não concebe as patologias sociais como extrapolação de domínios de racionalidades, mas, antes, como fenômenos negativos advindos do interior mesmo das práticas e estruturas sociais que são concebidas de modo a compor o núcleo gerativo das açóes e da possibilidade dos processos de formalização e institucionalização.

\section{Crítica À teoria da AÇÃo COMUNiCativa de Habermas}

Em Crítica do poder, Honneth estipula quatro "estágios reflexivos" através dos quais as premissas conceituais da teoria social crítica foram clarificadas. Tais estágios correspondem às formulaçôes originais de Horkheimer, passando pela filosofia da história de Adorno, a análise do poder de Foucault e a perspectiva comunicativa de Habermas. Honneth compreende esses estágios como uma história da teoria com pretensão sistemática, ou seja, uma reconstrução da Teoria Crítica na forma de um processo de aprendizado no qual estejam inscritos os contornos da solução aos problemas e dificuldades encontrados nessa história (HONNETH, 1991, p. xiii-xv). Por conseguinte, ele afirma que o modo específico como Horkheimer entrelaçou teoria e prática, baseado em Marx, pressupunha a análise, de dentro dos processos históricos, dos impulsos sociais. Nesse sentido, tendo a emancipação como horizonte, é

${ }^{4}$ HONNETH, A. Sofrimento de indeterminação: uma reatualização da Filosofia do Direito de Hegel (2007), p. 84.

${ }^{5}$ HONNETH, A. The social dynamics of disrespect: situating critical theory today (1999), p. 324. 
preciso realizar uma crítica desses impulsos e superar as formas estabelecidas de dominação (HONNETH, 1991, p. xiv). Isso significa tomar o "criticismo prático" como condição constitutiva do conhecimento crítico.

A tradição de pensamento fundada por Horkheimer, na medida em que viu arrefecer a esperança na emancipação, viu também crescer a importância da tarefa de garantir a crítica histórico-social, mas, ao mesmo tempo, percebeu igualmente a dificuldade crescente de cumprir essa tarefa. Na Dialética do Esclarecimento, Adorno e Horkheimer mostram que a racionalidade social proporcionada pelo capitalismo administrado é de caráter exclusivamente instrumental. Por isso, ela produz o conformismo ante a dominação, tornando-se apenas uma função de adaptação à situação vigente. A razão instrumental não produziria um conformismo ilusório que neutralizaria uma razão crítica capaz de tornar possíveis mudanças futuras. Antes, ela daria vazão a uma submissão voluntária, na medida em que não é possível visualizar outras possibilidades. A racionalidade crítica já não estaria inscrita na realidade, nem encontraria tendências concretas para a emancipação. $\mathrm{O}$ pessimismo da filosofia social de Adorno seria, para Honneth, o momento em que a tarefa reflexiva sucumbe diante da racionalidade instrumental. Será nesse sentido que a teoria habermasiana - e sua noção central de interação comunicativa - fornece a Honneth a chave teórica a partir de onde seria possível ultrapassar a aporia produzida pela teoria de Adorno. O pensamento de Habermas é fundamental para que Honneth possa desenvolver seu projeto, muito embora, como veremos, o próprio Honneth entenda que Habermas também não conseguiu construir uma saída produtiva ao problema resultante do pensamento de Adorno.

Os "estágios reflexivos" da reconstrução honnethiana e a apresentação crítica dos problemas e dificuldades contidos nesses passos sáo os seguintes: (1) As formulaçôes originais de Horkheimer a respeito das tarefas da Teoria Crítica não estariam em posição de resolver o problema básico esboçado por ele próprio, porque as premissas de sua filosofia da história - fortemente marcadas pelo papel central da dimensão do trabalho social - não permitiram que ele enxergasse as dimensóes da vida cultural e do conflito social como esferas de análise determinantes na crítica da dominação social (HONNETH, 1991, p. 32-56); (2) a reavaliação da dimensão do trabalho social empreendida por Adorno resultou numa filosofia negativa da história, forçada a interpretar toda ação social como simples extensão da dominação humana da natureza (HONNETH, 1991, p. 57-98); (3) mesmo tendo aberto o campo de análise 
das esferas sociais de interação e dos conflitos sociais, Foucault não delineou produtivamente bases normativas nem morais, em sua teoria do poder, tornando-a simplesmente uma explanação teórico-sistêmica dos processos sociais (HONNETH, 1991, p. 176-202); e, finalmente, (4) Habermas iniciou uma saída da aporia da Teoria Crítica através do seu conceito de ação comunicativa, o qual possibilitava entender as estruturas da dominação social como resultado de processos de entendimento comunicativo baseados em relaçóes intersubjetivas. Porém, Habermas teria desenvolvido a ideia da comunicação intersubjetiva em duas concepçóes diferentes de teoria da sociedade: uma, no sentido de uma lógica da racionalização (em conexão com a crítica da tecnocracia), outra, no sentido de uma dinâmica dos conflitos sociais (em conexấo com a crítica a Marx). Assim, a primeira ideia desenvolvida por Habermas corresponde ao modo hegemônico de interpretação da sua obra, mas somente a última se impóe, segundo Honneth, como alternativa profícua aos problemas da Teoria Crítica (HONNETH, 1991, p. 278-303). Vejamos:

A partir de Técnica e ciência como ideologia, Habermas efetiva, segundo Honneth, sua concepção dos conflitos como autonomizados nas estruturas institucionais. Isso significa que as açóes racionais se autonomizam e produzem a abstração do núcleo social de geração das açóes e, com isso, reificam tais açóes. Habermas, nesse momento, cederia demais ao modelo da dupla racionalização pelo qual a racionalidade técnica e estratégica provocaria uma "pressão de adaptação" no quadro institucional da sociedade e no mundo da vida sociocultural. "Trabalho" e "interaçáo", separados de maneira estanque, se tornariam posteriormente uma forma mais complexificada: "sistema" e "mundo da vida". Honneth vê tanto o "sistema" quanto o "mundo da vida" como abstraçôes indevidas, pois, entre outras coisas, gerariam "ficçôes complementares" como "[...] a existência de organizaçôes de ação livres de normas e [...] a existência de esferas de comunicação livres de poder" (HONNETH, 1991, p. 298).

Essa separação estanque posta em marcha por Habermas deriva, segundo Honneth, da união de aspectos da pragmática universal, da teoria da evolução social e da assimilação das hipóteses básicas da teoria dos sistemas. Ancorado nessas três frentes teóricas, Habermas desenvolve, na Teoria da ação comunicativa, uma virada teórico-comunicativa no diagnóstico geral da Dialética do Esclarecimento. No entanto, Honneth aponta que esses aspectos são responsáveis também pelo enrijecimento da concepção de organização social que enfatiza os processos de racionalização, em detrimento da práxis social na qual os grupos sociais estão 
envolvidos ${ }^{6}$. Tudo se passa como se Honneth censurasse Habermas por uma adesão excessiva ao diagnóstico sociológico weberiano. Ou seja, Habermas carregou nas tintas, ao pintar o processo moderno da autonomização das esferas de valor e deixou de lado os aportes teóricos de matriz hegeliano-marxianos relativos aos conflitos e lutas sociais.

Nesse sentido, Honneth mostra que o potencial teórico-comunicativo que Habermas anteviu através das formas comunicativas de vida - as quais se desdobram por meio dos conflitos dos grupos integrados culturalmente - teria sido utilizado apenas no sentido de continuar, num nível superior, o dualismo teórico-social usado na sua crítica à tese da tecnocracia (HONNETH, 1991, p. 301). Assim como Adorno havia localizado as tendências de desenvolvimento do presente, com o dualismo entre organização e indivíduo, Foucault, com o dualismo dos aparatos de poder e do corpo humano, Habermas teria construído seu diagnóstico do tempo, com o dualismo sistema e mundo da vida. Nesse sentido, ele subordinou, segundo Honneth, as potencialidades do paradigma comunicativo à teoria sistêmica (HONNETH, 1991, p. 302) que trabalharia com uma noção de sistema "puro" e livre de normas. Ao conceber a sociedade em dois níveis, enfatizar o entendimento e o consenso enquanto bases para a ação comunicativa e destacar a racionalidade instrumental como indispensável à reprodução material da sociedade, Habermas de certa forma deixaria de ampliar as possibilidades da crítica, porque as patologias sociais seriam compreendidas como extrapolação de domínios de racionalidades e não como fenômenos negativos advindos do interior das práticas e estruturas sociais.

Habermas perde acima de tudo [...] a aproximaçáo teórico-comunicativa que ele tinha inicialmente aberto: o potencial para o entendimento da ordem social como uma relação comunicativa mediada institucionalmente entre grupos integrados culturalmente que, tão logo o exercício do poder seja assimetricamente distribuído, toma lugar através do medium do conflito social. Somente uma elaboração consistente desta versão alternativa da teoria comunicativa da sociedade tornaria possível compreender as organizaçôes sociais que Adorno e Foucault confundiram como complexos de poder funcionando de uma maneira totalitária como construçōes frágeis que permanecem dependentes para sua existência do consenso moral de todos os participantes (HONNETH, 1991, p. 303).

\footnotetext{
6 "Habermas não dá aos grupos agentes um papel conceitual na sua teoria social. Ao invés disso, [...] ele conecta o nível dos sistemas de ação constituídos sistematicamente ao nível dos agentes individuais sem levar em consideração o estágio intermediário da práxis dos grupos integrados socialmente" (HONNETH, 1991, p. 285).
} 
Nota-se que o elemento enfatizado por Honneth como chave para a reconstrução e saída da aporia da Teoria Crítica é o conflito. A ênfase do autor de Crítica do poder na tematização dos conflitos expressa sua convicção na necessidade de tratar as lutas sociais enquanto lutas moralmente motivadas. Tal motivação não pode, de acordo com ele, ser buscada nos princípios ou fundamentos do consenso e do entendimento prático, isto é, em uma teoria linguístico-discursiva do mundo da vida, uma vez que se trata de um nível muito abstrato que separa indevidamente os processos de integraçáo sistêmica dos processos de integração social. Nesse sentido, Honneth afirma que o poder e os meios para a coordenação da ação social são considerados por Habermas "[...] somente no nível da integração sistêmica, de forma que todos os processos pré-sistêmicos de constituição e reprodução da dominação se perdem de vista” (HONNETH, 1991, p. 300-301). Quando a linguagem se torna o meio ideal da interação comunicativa, não se incorpora a importância da dimensão das pretensóes pré-argumentativas, aquelas que não tomam forma de argumentaçôes, mas que são dirigidas pelos indivíduos à sociedade e aos seus parceiros de interação na forma de conflitos sociais. Desse modo, o conflito social é visto por Honneth como a base da interação de tal modo que até mesmo a comunicação se mostra estruturalmente conflituosa. Portanto, será por meio da decifração do aspecto moral do conflito social que será possível um novo impulso à Teoria Crítica .

\section{CONFLITO E RECONHECIMENTO: O ASPECTO MORAL DA INTERAÇÁO SOCIAL}

Qual seria, então, a motivação moral das lutas e conflitos sociais? Essa resposta Honneth não oferece, em Crítica do Poder, muito embora, já no posfácio da segunda edição da obra em 1988, ele saliente que “[...] somente um estudo que tenha sucesso em tornar a ideia hegeliana de uma 'luta por

\footnotetext{
${ }^{7}$ Embora tal asserção certamente mereça o desenvolvimento de uma tese, seguramente o novo enfoque dado ao conflito por Honneth constitui um novo passo na história da Teoria Crítica, seja retomando intuiçôes fundamentais contidas nos escritos de Horkheimer da década de 1930, seja reconstruindo criticamente elementos da virada comunicativa de Habermas. Como salienta Trejo-Mathys, "[...] nós temos visto a evolução da teoria social crítica do paradigma da produçấo, até os paradigmas da comunicação e do reconhecimento. Nenhum destes tem revogado (aufgehoben) antigas variedades da teoria. Eles têm completado, acrescentado e inovado, e algumas vezes é claro, negligenciado insights dos teóricos anteriores". TREJO-MATHYS, J. The idea of a critical social theory: past, present and future (2008), p. 40 - trad. nossa.
} 
reconhecimento' sistematicamente útil para a teoria social, poderia talvez preencher as lacunas do argumento" ${ }^{\text {. }}$.

A transição de Crítica do Poder à Luta por reconhecimento é marcada pela tentativa de decifrar o aspecto moral da interação humana atravessada pelo conflito. Tal tentativa se concretiza através da "presentificação" e "atualização" da ideia da luta por reconhecimento, contida nos escritos de Jena do jovem Hegel. Nesses escritos, Hegel procurou desenvolver um conceito de conflito oriundo de impulsos morais e não mais de interesses utilitários. Isso permitiu ao autor construir um caminho para uma filosofia social dirigida para a compreensão de um "estado de liberdade comunicativamente vivida", o que evitou a compreensão da ação política e da soberania do Estado, por meio de uma racionalidade única com respeito a fins (HONNETH, 2003, p. 30). Tal conceito moral de conflito se resolve ainda nas formas elementares do convívio intersubjetivo, as quais são anteriores à formação do contrato social e de qualquer norma institucionalizada. $\mathrm{O}$ modelo de luta por reconhecimento concebida antes de qualquer formalização e institucionalização societária fornece a Honneth a chave para empreender sua reconstrução do social. Se o jovem Hegel havia modificado o modelo moderno de luta social (com a crítica a Maquiavel, Hobbes e Kant), pelo seu conceito de luta social moral, Honneth vai se inspirar na intuição hegeliana para contornar a abordagem dual de Habermas e fornecer uma visão menos "rígida" do social.

Honneth então realiza uma "presentificação" da ideia hegeliana, a fim de investigar o que nela pode ser pertinente para a intenção fundamental de construção de uma teoria social normativa. Seu empreendimento consiste em atualizar sistematicamente a intuição hegeliana de uma maneira empiricamente sustentada. Essa atualização é baseada na psicologia social de Georg Herbert Mead, e procura apresentar sistematicamente as estruturas sociais do reconhecimento, seus padróes e sua importância para a socialização e para a lógica moral dos conflitos sociais. Somente assim é possível, segundo Honneth, pensar um conceito moral de conflito social e de luta por reconhecimento que tenha raízes "empíricas", isto é, que contorne as bases idealistas da filosofia do jovem Hegel e propicie uma compreensão adequada acerca da eticidade social. Com a inserção da psicologia social de Mead, Honneth experimenta o

${ }^{8}$ HONNETH, 1991, p. xviii. É importante destacar que também as reflexôes de Barrington Moore Jr., em Injustiça: as bases sociais da obediência e da revolta (1987), exercem influência decisiva nesse momento, nas teorizaçóes de Honneth. Sobre esse aspecto, cf. HONNETH, A. The social dinamics of disrespect (1999), p. 329 n. 6, além de HONNETH, A. Justiça e liberdade comunicativa. Reflexóes em conexão com Hegel (2004), p. 112 n. 12. 
que para ele é o procedimento reconstrutivo, por intermédio da "atualização" sistemática da luta por reconhecimento do jovem Hegel. Dito de outro modo, após trazer a tese hegeliana para o momento presente, ele a "repóe" sobre premissas próprias do contexto pós-metafísico. Com isso, Honneth pretende afastar sua teoria de pressupostos metafísicos.

Mantendo a relação sempre frutífera que a Teoria Crítica possui com a psicanálise, Honneth recorre também aos textos de Donald W. Winnicott. Sua intenção, nesse momento, é demonstrar que essa teoria pode auxiliar na investigação do modo (conflituoso) como se dá o processo que vai da simbiose (intersubjetividade primária) entre mãe e filho até a individuação (autoafirmação) (HONNETH, 2003, p. 165). A abordagem winnicottiana se aproxima de Mead e Hegel, no sentido de que parte - a fim de compreender as condiçóes suficientemente boas da socialização das crianças - de uma concepção do relacionamento entre mãe e filho. Esse relacionamento compóe, segundo Honneth (2003, p. 164), um tipo de interação que não pode ser visto com importância secundária para o desenvolvimento do comportamento. Winnicott, segundo Honneth, com sua teoria das relaçóes de objeto - a qual representa em certa medida uma oposição ao modelo freudiano de psicanálise - investiga o modo como se constitui o processo de interação entre mãe e filho, que vai da simbiose, do "indiferenciado ser-um", até o momento em que eles aprendem a se amar como pessoas independentes e separadas?.

Com Mead e Winnicott se completa a formulação atualizadora das formas elementares da intersubjetividade que Honneth encontra no Hegel de Jena. $\mathrm{O}$ autor frankfurtiano dá forma materialista às formas elementares do convívio intersubjetivo e inicia uma caracterização do social que inclui também a materialização das outras formas do reconhecimento. Trata-se da fenomenologia empírica do reconhecimento, ou a estrutura das relaçóes sociais do reconhecimento. Essa abordagem preconiza três formas essenciais de reconhecimento (amor, direitos e solidariedade); três autorrelaçóes correspondentes (autoconfiança, autorrespeito e autoestima); três dimensóes afetadas da personalidade (natureza afetiva, imputabilidade moral e capacidades e propriedades); além dos componentes ameaçados da personalidade (integridade física, integridade social e dignidade) e as formas de desrespeito. Toda essa estrutura representa os fundamentos sociais das três esferas e âmbitos essenciais da atividade humana: "família" ou relaçóes

\footnotetext{
${ }^{9}$ Não vamos desenvolver a apropriação que Honneth faz de Mead e de Winnicott, porque essa questão vai além das pretensóes deste texto.
} 
amorosas, "sociedade civil" ou relaçôes jurídicas, "comunidade de valores" ou relações de solidariedade.

Para Honneth, compreender a gramática do surgimento e configuração dos movimentos sociais só é possível através da explicação da dinâmica inerente a essa estrutura - a dinâmica moral, a qual vai do desrespeito, passa pelo conflito e busca o reconhecimento. Daí a necessidade de compreender a lógica moral dos conflitos sociais e como o desrespeito pode se transformar em resistência. Se a lógica de surgimento desses movimentos tem raiz em experiências morais, então o conflito social náo deve ser entendido como um simples participante funcional num jogo de poder, mas como algo atravessado pelas exigências de reconhecimento.

Outra questão que emerge da compreensão da estrutura social e da lógica dos conflitos é aquela que pergunta pelo critério a ser definido para a avaliação das lutas sociais. Esse critério normativo deve ser posto tendo em vista a averiguação da positividade ou não das lutas no que concerne à realizaçáo saudável das formas do reconhecimento. Ele é construído por Honneth com base em uma concepção formal da eticidade, o qual define relaçôes de reconhecimento pós-tradicionais: ele diz respeito ao todo das condiçôes intersubjetivas, enquanto pressupostos normativos, pelas quais se chega à autorrealização individual. Não busca concepções axiológicas concretas de mundos da vida particulares, mas determinaçôes formais ou abstratas da vida boa, tendo em vista esses contextos interpretativos particulares. Do ponto de vista do conteúdo, esse critério guarda um teor específico que faz valer as condiçóes da autorrealização mais satisfatoriamente do que a noção kantiana de autonomia individual (HONNETH, 2003, p. 269 ss).Isso implica que a teoria do reconhecimento, por um lado, não se enquadra na tradição kantiana, porque, além das condiçóes para a autonomia do ser humano, ela procura garantir as condiçóes da autorrealizaçáo dos sujeitos como um todo, o que coloca a moral como um instrumento de ajuda ao objetivo universal da concretização de uma vida boa. Entretanto, a noção de bem não pode ser igualmente compreendida por convicçóes axiológicas particulares ou substanciais relativas a tradiçóes de comunidades singulares. Ela deve ser entendida a partir do ponto de vista universal que possibilite a comunicação da autorrealização, dirá Honneth, o que situa a teoria do reconhecimento entre a teoria moral de tradiçâo kantiana e as éticas comunitaristas, já que ela se orienta pelos objetivos da autorrealização humana e também pelo interesse em normas universais de comportamento (HONNETH, 2003, p. 269 ss). 
Desse modo, é possível afirmar que Honneth parte da formulação materialista das formas elementares do convívio e experiência intersubjetivas, passa pelas estruturas das relaçóes sociais, chega à elaboração das formas de desenvolvimento e evolução sociais baseadas no reconhecimento e, finalmente, fornece um padrão normativo de avaliação das lutas sociais, por meio de um conceito formal de eticidade. Com isso, ele amplia a conceituação do social e suas esferas, ao derivar das formas elementares da interação o âmbito da estrutura e gramática moral dos conflitos sociais.

\section{FUNDAMENTOS NORMATIVOS DA REALIDADE SOCIAL}

Após estabelecer, em Luta por reconhecimento, as dinâmicas das estruturas sociais, Honneth aprofunda essa investigação, em Sofrimento de indeterminação. Nesse momento, ele reatualiza a eticidade e o espírito objetivo da filosofia do espírito hegeliana, ao conceituar as esferas sociais normativas, as patologias sociais e as normas juridicamente positivadas como dependentes das esferas sociais normativas. Em várias passagens, ele caracteriza tanto o espírito objetivo quanto a eticidade por seu caráter revelador dos "fundamentos racionais" da realidade social ou, ainda, da "racionalidade" da realidade social (HONNETH, 2007, p. 83). Trata-se de uma interpretação que aprofunda a caracterização do social enquanto fundamento de qualquer formalização e institucionalização societária. Nesse momento, a abordagem do social realizada por Honneth se amplia e ele propóe um conceito de instituição proveniente diretamente das esferas sociais. Analogamente, ele volta a enfatizar o padrão normativo das formas do reconhecimento recíproco e das formas de autorrealização individual, mas desta vez resguardando certa estrutura de direitos, liberdades e deveres por meio de uma noção de vida boa. Para realizar essa tarefa, o autor volta à filosofia hegeliana, agora com intençóes de reatualizar ${ }^{10}$ a teoria do Estado presente na Filosofia do Direito. O procedimento segue de maneira “indireta”, isto é, nem o conceito substancialista de Estado nem o de espírito são reabilitados. O núcleo da reatualização são os conceitos de espirito objetivo

\footnotetext{
10 "Reatualização", pelo menos no contexto de Sofrimento de indeterminação, indica que elementos centrais da teoria a ser "reatualizada" são, de certa maneira, "inatualizáveis", isto é, impossíveis de serem repostos sob condições pós-metafísicas, o que implica que apenas alguns conceitos essenciais da teoria serão objetos da "reatualização". Esse procedimento pode ser considerado herdeiro da prática "reconstrutiva", no sentido de Habermas, ao menos dos princípios reconstrutivos que permaneceram vigentes no decorrer do desenvolvimento de suas obras, excetuando-se a reconstruçáo no sentido da teoria da evoluçáo social ancorada pela psicologia do desenvolvimento e no sentido da pragmática universal. Daí parecer que Honneth, no texto, utiliza tanto "reconstrução" como "reatualização" de maneira intercambiável.
} 
e eticidade, o que deixa claro que é por meio desses conceitos que Honneth julga ser possível caracterizar essencialmente as esferas sociais hoje.

Por eticidade compreende-se um quadro de exigências e pretensões que é composto das práticas de interação as quais devem garantir a autorrealização e de classes diferentes de açóes, as quais devem garantir o reconhecimento recíproco. Esse quadro não deve ser entendido, defende Honneth, como uma espécie de construtivismo moral, como organização de uma teoria ideal que apenas "constrói" princípios fundamentais de justiça, para depois se perguntar pelo modo de implementá-las (HONNETH, 2007, p. 115). Trata-se antes dos elementos de uma teoria da sociedade na qual os componentes sociais da modernidade fazem parte já das condiçôes das esferas de ação que liberam os critérios normativos expostos. Por isso, o termo "reconstrução normativa" faz sentido para Honneth a partir da caracterização dos propósitos daquilo que Hegel aborda, na última seção da Filosofia do direito (HONNETH, 2007, p. 116). A atualização da "doutrina da eticidade" hegeliana preconiza uma reconstrução das relaçóes modernas da vida, em um sentido normativo, quer dizer, ancorado nos padróes de interaçáo necessários à efetivação bem-sucedida da autorrealização individual. Nesse sentido, vale salientar os motivos que levam Honneth a recuperar a noção hegeliana de "espírito objetivo".

Essa parte de minha tentativa de reconstrução irá tratar, no essencial, da demonstração da seguinte tese: Hegel nos esclarece acerca do valor posicional exato que as liberdades moral ou juridicamente determinadas devem possuir em uma concepção abrangente de justiça moderna juntamente com um diagnóstico do efeito negativo que cada autonomização deve produzir sobre nosso mundo da vida social; para essa síntese ousada e muito particular da teoria da justiça e do diagnóstico de época é bastante útil seu conceito de "espírito objetivo", o qual, mesmo depois do abandono das pressuposiçôes metafísicas, ainda sustenta a idéia mediante a qual a realidade social é perpassada de fundamentos racionais que não podem ser violados sem conseqüências para nossa auto-relação. (HONNETH, 2007, p. 83-84)

A importância do conceito de "espírito objetivo", despido de sua essência metafísica, está no fato de ele conter a ideia de que a realidade social é constituída de fundamentos racionais que, uma vez violados, causam prejuízos à autorrealização dos indivíduos. Esses fundamentos racionais são as próprias esferas e práticas sociais estruturadas pelo reconhecimento. Os direitos universais estabelecidos pertencem apenas mediatamente à esfera do indivíduo 
e primeiramente às relaçóes e estruturas sociais, às formas de "existência" sociais necessárias para a realização da "vontade livre". Essa constatação abre a perspectiva de caracterização das esferas sociais como núcleo e fundamento das formalizações e institucionalizações societárias no pensamento de Honneth.

Pela atualização do espírito objetivo e da doutrina da eticidade, Honneth compóe uma teoria normativa da modernidade, porque para ele a doutrina da eticidade contém em si as esferas ético-sociais cujo núcleo constitui o fundamento e possibilidade das instituiçôes sociais. Com isso, é possível caracterizar teoricamente a modernidade através de uma "reconstrução das esferas sociais da modernidade", e não simplesmente por intermédio de uma reconstrução das instituiçôes da modernidade. Assim, a teoria normativa da modernidade precisa mobilizar as estruturas e relaçóes éticas da vida social. Dito de outro modo, ela é capaz de lidar com o padrão de práticas intersubjetivas que permitem aos membros da sociedade a possibilidade da autorrealização, na medida em que se relacionam uns com os outros, enquanto relacionamento moral baseado no reconhecimento recíproco. O caráter dessa teoria normativa da modernidade, como reconstrução das esferas sociais modernas, dá o tom da crítica anti-institucionalista que Honneth faz à teoria do Estado contida na Filosofia do direito de Hegel. Tal crítica tem como alvo aquilo que Honneth chama de "superinstitucionalização" das esferas da eticidade (HONNETH, 2007, p. 124 ss).

Para compreender esse movimento, é preciso lembrar que as esferas da eticidade são constituídas essencialmente, na Filosofia do direito, pelos âmbitos da "família", "sociedade civil" e "Estado". Segundo Honneth, Hegel havia caracterizado a relação existente entre esses três âmbitos como uma relação hierárquica, que segue uma linha "ascendente", cuja explicação, no sentido da atualizaçáo, não necessita da referência aos pressupostos lógicos do sistema. Hegel supóe uma sequência de carência, interesse e honra, correspondentes à família, sociedade civil e Estado, respectivamente. Nessa sequência, haveria um aumento da personalidade individual, ou da formação racional da individualidade, de modo que os esquemas cognitivos seriam construídos e desenvolvidos gradualmente no horizonte da sensação (família), da racionalidade com respeito a fins (sociedade civil) e da razão (Estado). Honneth afirma a necessidade de se supor que há em Hegel "[...] a tese sistemática de que as chances de individualização de um sujeito aumentam com o grau de sua capacidade de universalização das próprias orientaçóes”. Isso possibilita notar que a "[...] sequência de carência, interesse e honra significa um esquema de 
nivelação no qual o processo de individualização é equiparado a um processo de descentramento progressivo" (HONNETH, 2007, p. 123). No entanto, esse "descentramento" seria, para Hegel, limitado pelo interesse comum da comunidade concreta. A formação racional e descentrada da subjetividade compóe assim a hierarquia normativa encontrada na sequência das diferentes esferas da eticidade. Sua importância reside no fato de revelar as condiçóes de realização da liberdade individual nas esferas das sociedades modernas, e de poder decifrar as relaçóes existentes entre as formas de subjetividade, de reconhecimento e autorrealização.

Por conseguinte, a crítica é dirigida exatamente ao modo como são caracterizadas essas três esferas e a relação entre elas. Segundo Honneth, Hegel enfatiza equivocadamente o caráter institucional de cada esfera e perde de vista o potencial inerente às práticas e relaçôes éticas de cada um desses âmbitos. No âmbito da "família", Hegel praticamente exclui o componente da "amizade", ao deixar a análise da realização da liberdade circunstanciada apenas ao espaço interior da pequena família burguesa. Amigos também se relacionariam de acordo com o padrão do reconhecimento recíproco da "impossibilidade de substituir o outro", e até mesmo constituiriam seus esquemas cognitivos através das relaçóes de amizade, aponta Honneth. A ausência da "amizade", na análise de Hegel, significa uma deficiência ainda maior, porque sinaliza para o fato de que

[...] tais relaçóes de interação da sociedade moderna só podem ser compreendidas como elemento social da eticidade que incide sobre as prerrogativas de organização do Estado esão, desse modo, institucionalizáveis de acordo com o direito positivo; pois sem tal possibilidade de um acesso estatal, as esferas correspondentes não teriam sequer base de durabilidade, confiabilidade e instaurabilidade necessárias para se falar de uma condição de liberdade para nós disponível (HONNETH, 2007, p. 131).

A família, por meio do contrato matrimonial, seria preferida em lugar da amizade e das relações afetivas não institucionalizadas, "contingentes". A eticidade hegeliana não comportaria os elementos "contingentes", pois necessitaria das relaçóes "estáveis" de comunicação das sociedades modernas. Honneth salienta a insistência com que Hegel trata da necessidade da institucionalizaçáo positivada juridicamente. No entanto, ele lembra que, sob o rótulo de "instituiçáo", poderiam ser compreendidas também, de certo modo, as práticas de ação estabelecidas em rotinas e hábitos intersubjetivos, os 
“costumes” - que, muito embora não sancionados juridicamente pelo Estado, possuem "[...] 'firmeza' e estabilidade suficientes para não estarem submetidos permanentemente aos 'caprichos' de nossos sentimentos" (HONNETH, 2007, p. 133). Se essa noção de "instituição" tivesse tido mais ênfase, talvez pudesse ter lançado alguma luz sobre os procedimentos hegelianos ligados à primeira esfera da eticidade, uma vez que, com alguns ajustes, ela poderia representar hábitos adquiridos culturalmente e incluir nas esferas éticas a relação da amizade. Honneth defende, portanto, que a noção de "instituição" poderia ser compreendida enquanto

\begin{abstract}
[...] práticas de ação que são dispensadas da rápida mudança ao assumirem a forma de rotinas e hábitos partilhados intersubjetivamente, ou seja, de "costumes", podem ser, de certo modo, entendidas como "instituiçōes"; ainda que falte nelas o ancoramento em sançôes jurídicas do Estado, possuem, no entanto, "firmeza" e estabilidade suficientes para não estarem submetidas permanentemente aos "caprichos" de nossos sentimentos (HONNETH, 2007, p. 133).
\end{abstract}

Assim, a noção de "instituição" proposta por Hegel poderia ser mais bem compreendida se fosse derivada dos "costumes", dos hábitos adquiridos culturalmente. A centralização nas formas institucionalizadas de relação limita e diminui os aspectos que podem ser atribuídos às características da liberdade nas sociedades modernas. Teria sido mais razoável, afirma Honneth, se Hegel tivesse deixado um espaço, no complexo das esferas do reconhecimento, para a ação em sua forma de institucionalização social. Ele poderia antever, pois, que as relações de comunicação são produzidas no processo de modernização social. Com isso, apesar de se desenvolverem em direção à institucionalização, elas não poderiam ser reduzidas ao resultado desse processo, à "instituiçâo", porque se caracterizam como hábitos que estão sempre em transformação e adaptação, já que partem dos elementos motivacionais da ação sempre contextualizados. Se a Filosofia do Direito pudesse ser compreendida nesses termos, aquilo que “[...] antes foi chamado de 'reconstrução normativa' não significaria apenas reconstruir realidades juridicamente institucionalizadas". Mas significaria, de fato, "[...] reconstruir as esferas sociais de valor da modernidade que se caracterizam pela ideia de uma combinação determinada de reconhecimento recíproco e autorrealização individual" (HONNETH, 2007, p. 136).

Em decorrência, a doutrina da eticidade hegeliana padece, de acordo com Honneth, de uma tendência a superinstitucionalização de suas esferas 
que enfraquece o potencial do diagnóstico de época hegeliano, assim como esconde as verdadeiras fontes da liberdade:

[...] ainda que tudo nela [na doutrina da eticidade] esteja disposto de tal maneira que se constitua nas três esferas apenas um padrão de interação capaz de garantir a liberdade, essa intençáo formal não pode ser realizada porque seu ponto de vista está voltado muito fortemente para as formas concretas de organizaçáo. (HONNETH, 2007, p. 141)

Embora o capítulo da "eticidade" da Filosofia do Direito tenha a intenção de examinar as estruturas normativas das sociedades modernas, para tentar averiguar as condiçôes historicamente constituídas da liberdade individual, ele confundiria essa tarefa com a pretensão de analisar as instituições as quais legitimam as formas "concretas" de organização, principalmente aquelas constituídas juridicamente. Como salienta Honneth, o problema se estenderia à esfera do Estado, na medida em que a autorrealização dos sujeitos que ocorre na "vida universal" parece mesmo náo considerar a ideia de uma liberdade pública. Esse "universal” pode ser caracterizado muitas vezes como o significado ético do Estado, ou seja, uma prática coletiva a partir de onde o reconhecimento das atividades do outro é expresso na medida em que elas contribuem para as finalidades perseguidas em comum. No entanto, ele se apresenta como um universal "substancial", em que o papel do sujeito como "cidadáo do Estado", ou "súdito a serviço", parece preponderar em detrimento do papel do cidadão capaz de atuar numa esfera pública política e na formação democrática da vontade. Assim, não haveria

[...] a previsão de um lugar único no qual os "cidadãos do Estado" pudessem reunir-se para deliberar em conjunto sobre como deveriam ser qualificados os fins considerados "universais"; não se encontra na doutrina do Estado de Hegel o menor vestígio de idéia de uma esfera pública política, da concepção de uma formaçáo democrática da vontade. (HONNETH, 2007, p. 144).

Mesmo estabelecida a legitimidade do Estado, pelo consentimento livre de cada cidadáo, os membros da sociedade náo gozam de procedimentos de deliberação pública e de formação de opinião. Dessa maneira, Hegel dá tanta importância ao Estado que este adquire o papel de organizador das outras esferas éticas de interação, resultando na ênfase das relações legalmente 
institucionalizadas, no que concerne à efetivação da liberdade nos âmbitos das diversas esferas de interaçáo (HONNETH, 2007, p. 132).

Finalmente, a preocupação com relação à eticidade e à atualização do espírito objetivo - e igualmente com a crítica à superinstitucionalização das esferas ético-sociais, em Hegel - dá o tom da abordagem adotada por Honneth. Assim, ela mantém seu núcleo nas esferas sociais e na conceitualização do social, enquanto fonte materialista e conflituosa tanto das açóes e movimentos sociais quanto dos processos de formalização e institucionalização das normas societárias.

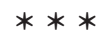

Com essa recuperação crítica do pensamento do jovem Hegel, Honneth pretende evitar a abordagem linguística de Habermas e a lógica de racionalização do mundo da vida que lhe é própria, porque um dos propósitos de Honneth é não negligenciar os fenômenos advindos do interior mesmo das práticas e estruturas sociais. Em Luta por reconhecimento, ele tenta construir uma base de teoria social comunicativa que leve em conta uma nova conceituação das esferas sociais, desmembrando o que para ele é o "déficit sociológico" da Teoria Crítica. Trata-se de delinear uma filosofia do social que dê conta de elucidar a realidade interativa, ao identificar o ponto de vista crítico da teoria no interior mesmo das práticas e relaçôes entre os indivíduos e grupos sociais. Esta filosofia do social enfatiza a luta e o conflito social como o núcleo estruturante e de onde são possíveis as açôes e as instituiçôes sociais. Por isso, Honneth dá forma a um conceito de luta social que focaliza as práticas do desrespeito - ou do não-reconhecimento - das identidades pessoais e coletivas. Ao mesmo tempo, ele busca delinear, a partir dessas práticas, quais as formas estruturais do reconhecimento que mostram o resultado do desenvolvimento dos processos de construção da identidade desde as esferas mais elementares da interação. Tal abordagem é rica para a Teoria Crítica, na medida em que procura o elemento crítico na denuncia enfática de práticas que são vivenciadas e experienciadas moralmente como lesão de noções intuitivas de dignidade e justiça. A tortura, a degradação física e moral, a privação de direitos são exemplos genuínos do que uma teoria crítica deve censurar.

Do ponto de vista do delineamento conceitual que deve dar base teórica aos posicionamentos críticos, a perspectiva de Honneth procura suprir 
um fundamento materialista (ou que apresente o caráter de uma "inflexão" empírica) para a luta por reconhecimento e para a intersubjetividade. Uma intersubjetividade que, enquanto núcleo da interação comunicativa, não nega uma dimensão metodológica dos entendimentos linguísticos, porém, procura decifrar a "infraestrutura" moral das interaçôes entre indivíduos "naturais" e "corpóreos", cuja vivência no mundo é experienciada de forma moral. Trata-se de dar corpo às formas elementares do convívio intersubjetivo, assim como às estruturas das relaçóes sociais e à gramática moral dos conflitos sociais. É com a caracterização desses três elementos fundamentais das esferas sociais que Honneth procura enfatizar em Luta por reconhecimento o papel central que essas esferas - articuladas aos grupos sociais - desempenham para a compreensão crítica da sociedade moderna. Com esse aparato conceitual, ele visa a mostrar que a Teoria Crítica não pode abstrair as experiências e vivências dos sujeitos envolvidos nas relaçôes e conflitos sociais, visto que são eles que amparam e fundamentam as formalizaçóes, os processos de racionalização e de institucionalização societários. Desse modo, Honneth busca colocar na posição de protagonista as relações comunicativas e as lutas sociais por reconhecimento, e trata de redirecionar os objetivos da Teoria Crítica para a elucidação categorial da realidade social.

Já em Sofrimento de indeterminação, pode-se constatar que, de certa maneira, Honneth continua a "elucidar categorialmente a realidade social". Contudo, desta vez, preocupando-se com os modelos de liberdade comunicativa próprios das esferas sociais normativas da modernidade e com as esferas sociais do reconhecimento. Com efeito, elas se mostram como núcleo irredutível dos processos de institucionalização e positivação jurídicos. Nesse momento, a perspectiva honnethiana se revela talvez com maior nitidez, uma vez que é a partir da crítica à "superinstitucionalização" da eticidade na Filosofia do Direito de Hegel que ele afirma a insuficiência da autonomização institucional das normas e das relaçóes comunicativas. Sua crítica pode ser dirigida tanto à ideia da racionalizaçáo do mundo da vida como objeto privilegiado da análise crítica, quanto à ideia da constituição autônoma e diferenciada das normas positivadas juridicamente. É possível entender aqui que tais críticas se orientam em oposição tanto à teoria da ação comunicativa habermasiana quanto à teoria do direito contida em Direito e Democracia.

Podemos compreender que o pensamento social de Honneth procura se contrapor à duplicidade das esferas racionais como "complexos institucionais", tal como propôe a teoria da ação comunicativa de Habermas. 
Nesse sentido, Honneth procura criticar também o caráter diferenciado do direito positivo na teoria discursiva do direito habermasiana. Assim, tanto o domínio da racionalidade sistêmica quanto o da comunicativa têm suas raízes nas esferas sociais de geração das açôes e esse núcleo social não pode ser abstraído ou tomado secundariamente ${ }^{11}$. Desse modo, as relaçôes "enrijecidas" institucionalmente permeiam toda ordem social. Entretanto, o núcleo motivador e central dos desenvolvimentos e mudanças históricos encontrase nas relaçóes comunicativas entre grupos integrados social e culturalmente.

Nesse sentido, se, para Habermas, o mundo da vida era constituído por sujeitos falantes em relação de entendimento entre si, para Honneth, as relaçóes sociais não mais bem compreendidas através da noção de reconhecimento, porque ela denota uma preocupação maior com a interação comunicativa e com as experiências sociais ancoradas nas relaçóes e vivências concretas dos sujeitos.

O processo emancipatório no qual Habermas ancora socialmente a perspectiva normativa de sua Teoria Crítica não está de forma alguma refletido tal como um processo nas experiências morais dos sujeitos envolvidos. Pois eles vivenciam uma violação do que podemos chamar suas expectativas morais, isto é, seu 'ponto de vista moral', não como uma restrição das regras de linguagem intuitivamente dominantes, mas como uma violação de pretensões de identidade adquiridas na socialização. Um processo de racionalização comunicativa do mundo da vida pode desdobrarse historicamente, mas nấo está refletido nas experiências dos sujeitos humanos como um estado moral de coisas. (HONNETH, 1999, p. 328)

Honneth não compreende os sujeitos como "falantes" antes mesmo de se "reconhecerem", o que implica uma ampla relação sensível, concreta e intrinsecamente conflituosa entre os sujeitos. Essa compreensão contrasta com a ênfase habermasiana no entendimento. A interação comunicativa, desse modo, é trabalhada por Honneth em um nível mais elementar, pré-linguístico, trabalho que pressupóe um novo conceito de "social" que pode, segundo ele,

\footnotetext{
${ }^{11}$ Embora isso não signifique que Honneth não se preocupe com os aspectos sistêmicos das relaçôes sociais. Ele desenvolve uma reflexão preocupada, por exemplo, com a esfera do trabalho desde seus escritos de "juventude", como Work and Instrumental Action: On the Normative Basis of Critical Theory (1995), publicado originalmente em 1980. Sobre essa questão, e mais especificamente sobre a reflexão possível do paradigma do reconhecimento acerca das "realidades econômicas" ou "materiais", cf. SMITH, Nicholas H. Work and the Struggle for Recognition (2009), e sobre a teoria do reconhecimento como "revisão da concepção crítica do trabalho", cf. MOLL, Karl N. The enduring significance of Axel Honneth's critical conception of work (2009).
} 
decifrar adequadamente as fontes daquilo que em Habermas foi fracionado em "mundo da vida" e "sistema". Honneth desloca para o centro da teoria as relaçôes morais pré-linguísticas bem como das práticas e esferas ético-sociais; com isso, ele procura não abstrair os fenômenos patológicos, "exportando-os" para complexos de razão. Assim, o autor não subestima o papel determinante dessas patologias na experiência "vivida" dos indivíduos. Da mesma forma, ele pretende não negligenciar o potencial de organização emancipatória contido nos movimentos e reivindicaçóes por reconhecimento e dignidade. $\mathrm{O}$ conceito formal de eticidade e os modelos de liberdade comunicativa da teoria normativa da modernidade servem como critérios normativos para a avaliação dessas lutas sociais em referência ao seu caráter emancipatório ou reacionário.

Tal posição revela a preocupação em considerar a importância das esferas sociais em relação ao seu papel fundador de movimentos e reivindicaçóes que visam a formas de emancipação e libertação do sofrimento e do desrespeito, nas sociedades capitalistas modernas. Esses fenômenos patológicos muitas vezes são encobertos por configuraçóes demasiadamente institucionalistas, cujo funcionamento em muitos casos pode "barrar" a possibilidade de articulação e reivindicação coletivas por reconhecimento, dignidade e justiça. Possivelmente, a ênfase no papel das esferas e grupos sociais torna delicada a análise dos arranjos institucionais das sociedades complexas, tais como a institucionalização do direito ${ }^{12}$ ou o funcionamento do campo político, nas sociedades modernas ${ }^{13}$. Contudo, a posição honnethiana não pode ser

\footnotetext{
${ }^{12}$ Tal como Saavedra e Sobottka questionaram: "[...] como é possível combinar a ideia hegeliana de luta por reconhecimento com as instituiçôes de um estado democrático de direito?”, e "como é possível pensar instituiçóes a partir do conceito de reconhecimento, dado que Honneth, desde o início, e ainda hoje, pretende desenvolver esse conceito sem se fazer valer, como Habermas, da teoria dos sistemas?". SAAVEDRA, G.; SOBOTTKA, E. Introdução à teoria do reconhecimento de Axel Honneth (2008), p. 17-18. Ou ainda, como comenta Werle: "[...] as concepçóes de pessoa de direito e de pessoa moral estão fundidas numa única forma de reconhecimento jurídico moral, formando uma única identidade prática. Essa não diferenciação entre moral e direito impede Honneth de compreender o modo complexo de legitimação do direito nas sociedades modernas" (WERLE, 2004, p. 77).

${ }^{13}$ Ao defender que, pelas premissas honnethianas, seria necessária a introdução de novos critérios normativos diferentes daqueles da categoria do reconhecimento, Kalyvas (1999) acredita que "Honneth não discute diretamente as consequências políticas de sua teoria moral do reconhecimento, deixando sem respostas questôes relacionadas a problemas de estratégia política, táticas de confrontaçáo e políticas democráticas" (KALYVAS, 1999, p. 105). Também nesse sentido, Werle e Melo apontam para um "déficit político" na obra de Honneth: "[...] se por um lado Honneth quer sanar o déficit sociológico da Teoria Crítica, por outro, sua teoria acaba gerando um déficit político, no sentido de que não há nenhuma preocupação em explicitar um princípio de justificação pública, em que os próprios cidadãos possam decidir quais formas de reconhecimento e princípios de justiça são legítimos ou ilegítimos". In: Reconhecimento e justiça na Teoria Critica da sociedade em Axel Honneth (2008), p. 197-198.
} 
confundida com um anarquismo social ou uma apologia ao espontaneísmo de movimentos coletivos sem uma justificaçáo pública racional. Honneth está preocupado com modelos de práticas democráticas inseridas no Estado democrático de direito, daí a ênfase nos modelos de liberdade e autorrealização individuais e coletivos, assim como o reconhecimento de demandas identitárias e sociais. Nesse sentido, sua proposta poderia ser interpretada como uma tentativa de delimitar conceitualmente uma espécie de "eticidade democrática", isto é, os laços próprios do modo de vida democrático.

O que a teoria normativa honnethiana positivamente pode enfatizar e indicar é a necessidade de maior "abertura" dos âmbitos institucionais para os movimentos coletivos que lidam e interpretam, em ampla medida, práticas sociais e institucionais como sendo desrespeitosas ao seu modo de vida ${ }^{14}$. A preocupação com a formação da liberdade, com os processos de aprendizagem sociais e com o diagnóstico de patologias que afetam o mundo da vida seguramente fornece um contraponto, cuja positividade é indicar maior participação dos sujeitos sociais. Com isso, é possível visualizar a ampliaçáo da participação e o incentivo de certo protagonismo social, nos processos de construção e configuração da política democrática. A teoria normativa honnethiana apresenta ainda a positividade de se configurar como mais um modelo de teoria da modernidade que objetiva identificar potenciais emancipatórios das relaçóes comunicativas. Ela não cede ao diagnóstico pessimista que vê na modernidade o contínuo e exclusivo desenvolvimento de relaçóes instrumentais ou sistêmicas.

Assim, é possível afirmar que o empreendimento honnethiano tem por mérito e potencial revelar que os conflitos podem ser entendidos como conflitos morais e comunicativos, no plano do desenvolvimento das identidades coletivas e das sociedades. Tal proposta pode até mesmo, como muitas pesquisas têm procurado salientar, indicar limites para a teoria procedimentalista e discursiva de Habermas, bem como procurar

\footnotetext{
${ }^{14}$ Nesse sentido, no contexto de sua defesa do reconhecimento como condição necessária para o desenvolvimento "sadio" do processo democrático e de que a principal funçáo do direito penal deveria ser proteger as relaçôes de reconhecimento, Saavedra assinala que a teoria do reconhecimento tem por mérito estabelecer uma ligaçáo essencial entre o reconhecimento e o conceito de dignidade da pessoa humana. Cf. SAAVEDRA, G. Segurança vs. dignidade: o problema da tortura revisitado pela criminologia do reconhecimento (2009), p. 100 ss.
} 
integrá-la numa concepção ampliada de teoria social 5 . Com isso, ela revela os potenciais não explorados de uma teoria social crítica interessada nos conflitos e nas lutas sociais enquanto fundamentos sociocomunicativos da crítica, o que permite o desenvolvimento de uma nova Teoria Crítica, como quer o próprio Honneth, nos moldes de uma interpretação hegeliana de esquerda.

SILVA, Hélio Alexandre; RAVAGNANI, Herbert Barucci. Structures and social foundations: Honneth's reading of Habermas. Trans/Form/Ação, Marília, v. 36, n. 2, p. 155-178, Maio/Ago., 2013.

\begin{abstract}
This article aims to highlight, in the form of brief general notes, the broad outlines of Honneth's critique of some aspects of Habermas' thought. Honneth's critique is guided by an investigation of the moral and normative criteria of social struggles, which Honneth appropriates in a critical fashion from the young Hegel. Honneth's central point is that the possibilities of interactivecommunicative experience cannot be summarized in, or taken exclusively from, linguistic interaction, nor can the latter be pursued in its ideal aspect without the presupposition of the conflicting contexts in which it is always inserted.
\end{abstract}

KEYWORDS: Social conflict, intersubjectivity, Habermas and Honneth.

\title{
REFERÊNCIAS
}

DERANTY, Jean-Philippe; RENAULT, Emmanuel. Politicizing Honneth's Ethics of Recognition. Thesis Eleven, no 88, p. 92-111, fevereiro de 2007.

ERMAN, Eva. Reconciling communicative action with recognition: thickening the "inter" of intersubjectivity. Philosophy \& Social Criticism, vol. 32, no 03, p. 377-400, 2006.

HABERMAS, Jürgen. (Técnica e ciência como "Ideologia". Trad: Artur Morão, Lisboa: Ediçōes 70, s/d.

Direito e democracia: entre facticidade e validade. Rio de Janeiro: Tempo Brasileiro, 2003, Vol. I e II.

Teoría de la acción comunicativa: critica de la razón funcionalista. Madrid: Taurus Humanidades, 1992 (Vol. II).

${ }^{5}$ Cf. ERMAN, E. Reconciling communicative action with recognition: thickening the "inter" of intersubjectivity (2006); DERANTY, J-P.; RENAULT, E. Politicizing Honneth's Ethics of Recognition (2007). 
- Teoría de la acción comunicativa: racionalidad de la acción y racionalización social. Madrid: Taurus Humanidades, 1999 (Vol. I).

HEGEL, G. W. F. Introdução à filosofia do direito. Trad: Marcos Lutz Müller. Clássicos da Filosofia: Cadernos de Traduçáo. Campinas, IFCH/UNICAMP, 2005.

HONNETH, Axel; JOAS, Hans. Social action and human nature. Trad: Raymond Meyer. Cambridge: Cambridge University Press, 1988.

HONNETH, Axel. The critique of power: reflective stages in a critical social theory. Trad: Kenneth Baynes. $1^{\text {st }}$ ed. Cambridge: MIT Press. 1991.

. Work and Instrumental Action: On the Normative Basis of Critical Theory. In: . The Fragmented World of the Social. Albany, NY: SUNY Press, 1995, p. 15-49.

. The social dynamics of disrespect: situating critical theory today. In: DEWS, Peter (Org.). Habermas: a critical reader. Oxford: Blackwell Publishers, 1999, p. 320-337.

. Luta por reconhecimento: a gramática moral dos conflitos sociais. Trad: Luiz Repa. São Paulo: Ed. 34, 2003.

Justiça e liberdade comunicativa. Reflexões em conexão com Hegel. Revista Brasileira de Estudos Políticos. Belo Horizonte, Universidade Federal de Minas Gerais, ${ }^{\circ}$ 89, p. 101-120, jan./ jun. 2004.

. Sofrimento de indeterminação: uma reatualização da Filosofia do Direito de Hegel. Trad: Rúrion Soares Melo. São Paulo: Singular, Esfera Pública, 2007.

KALYVAS, Andreas. Critical Theory at the Crossroads: Comments on Axel Honneth's Theory of Recognition. European Journal of Social Theory, vol. 2, no 01, p. 99-108, 1999.

MEAD, George Herbert. Mind, Self and Society: from the standpoint of a social behaviorist. Chicago, The University of Chicago Press, 1967.

MOLL, Karl N. The enduring significance of Axel Honneth's critical conception of work. Emergent Australasian Philosophers, Issue 2, p. 01-16, 2009.

MOORE, Barrington Jr. Injustiça: as bases sociais da obediência e da revolta. São Paulo: Brasiliense, 1987.

NOBRE, Marcos. Luta por reconhecimento: Axel Honneth e a Teoria Crítica. In: HONNETH, A. Luta por reconhecimento: a gramática moral dos conflitos sociais. Trad: Luiz Repa. São Paulo: Ed. 34, p. 07-19, 2003 a.

SAAVEDRA, G. Segurança vs. dignidade: o problema da tortura revisitado pela criminologia do reconhecimento. Veritas. Porto Alegre, vol. 53, no 02, p. 90-106, abr./jun. 2008.

; SOBOTTKA, Emil Introdução à teoria do reconhecimento de Axel Honneth. Civitas, Porto Alegre, v.8, n¹, p. 9-18, 2008.

SMITH, Nicholas. Work and the Struggle for Recognition. European Journal of Political Theory, vol. 08, no 01, p. 46-60, 2009.

TREJO-MATHYS, Jonathan. The idea of a critical social theory: past, present and future. Civitas, Porto Alegre, v.8, n¹, p. 19-45, 2008. 
WERLE, Denílson L. Lutas por reconhecimento e justificação da normatividade. (Rawls, Taylor e Habermas). 2004. Tese (Doutorado em Filosofia) - FFLCH/ USP, São Paulo, 2004.

; MELO, Rúrion S. Reconhecimento e justiça na teoria crítica da sociedade em Axel Honneth. In: NOBRE, M. (Org.). Curso livre de Teoria Critica. Campinas: Papirus, 2008, p. 183-198.

Recebido em: 02.01.2012

Aceito em: 03.12.2013 
ALEXANDRE, H.; RAVAGNANI, H. B. 